\title{
Congenital adenoma of the iris and ciliary body: light and electron microscopic observations
}

\author{
Ian G Rennie, M Andrew Parsons, Colin A L Palmer
}

\begin{abstract}
A 23-year-old man had a lesion in the right inferior iris which appeared to have enlarged since it was first seen when the patient was aged 5 years. The lesion was excised by a partial iridocyclectomy. Histopathologically the neoplasm was composed of both pigmented and non-pigmented cells. Pseudoacini, containing acid mucopolysaccharides, were present throughout the tumour matrix. Electron microscopically the non-pigmented cells were found to possess a convoluted plasmalemma, abundant rough endoplasmic reticulum, and numerous desmosomes and gap junctions. The pigmented cells contained large, round, mature melanosomes, occasional premelanosomes, and desmosomes, which resembled the posterior pigment epithelium of the iris. The intercellular matrix contained fine collagen fibrils resembling vitreous. We believe that this neoplasm represents a congenital adenoma of the ciliary body and iris.

(Br f Ophthalmol 1992; 76: 563-566)
\end{abstract}

True neoplasms arising from the nonpigmented ciliary epithelium are extremely rare. ${ }^{1-13}$ Zimmerman' has proposed that they are classified into congenital and acquired lesions, based on their histological appearances. Congenital lesions arise from the primitive medullary epithelium and include glioneuromas and medulloepitheliomas. Acquired neoplasms and pseudoneoplasms of the non-pigmented ciliary epithelium usually occur in adulthood; they arise from the fully differentiated ciliary epithelium and include: psuedoadenomatous hyperplasia (reactive and senile), adenomas, and adenocarcinomas. ${ }^{14}$ Lesions arising from the pigmented epithelium are equally uncommon and include adenomas ${ }^{15-18}$ and adenocarcinomas. ${ }^{19} 20$ Adenomas of the iris pigment epithelium have also been described. ${ }^{21}{ }^{23}$ We report a congenital adenoma of the ciliary body and iris, which contained well differentiated pigmented and non-pigmented elements.

\section{Case report}

The patient, a 23-year-old man, first presented to the eye department aged $51 / 2$ years with a hyphaema in the right eye following an injury with a cardboard toy. The patient was admitted for bed rest, and upon resolution of the hyphaema, was noted to have a greyish mass in the iris inferiorly. The patient's parents commented that there had always been a 'mark' on the iris, and a photograph taken when the patient was 26 months old confirmed this. Staff opinions were sought and it was the consensus that the lesion was benign, possibly a leiomyoma, and should best be managed by periodic observation.

When the patient was reviewed in January 1987 the lesion appeared to have enlarged slightly and further staff opinions were sought. On examination the uncorrected visual acuities were $20 / 15$ in both eyes. Slit-lamp biomicroscopy revealed a nodular, variably pigmented, wedge shaped lesion involving the inferior iris and angle (Fig 1). The iris stroma was deficient overlying the lesion and an adjacent cortical lens opacity was present. Prominent dilated blood vessels were present on the surface of the lesion and in the adjacent iris stroma. Dilated episcleral (sentinel) vessels were noted overlying the adjacent sclera. The remainder of the ocular examination was normal. In view of the possible enlargement and uncertain diagnosis, the lesion was locally excised under general anaesthesia. Postoperative progress was uneventful and the visual acuity 3 months after surgery was correctable with a contact lens to 20/20. The patient had been followed for 3 years without any signs of recurrence.

\section{Pathological examination}

LIGHT MICROSCOPY

Microscopically the neoplasm was composed of

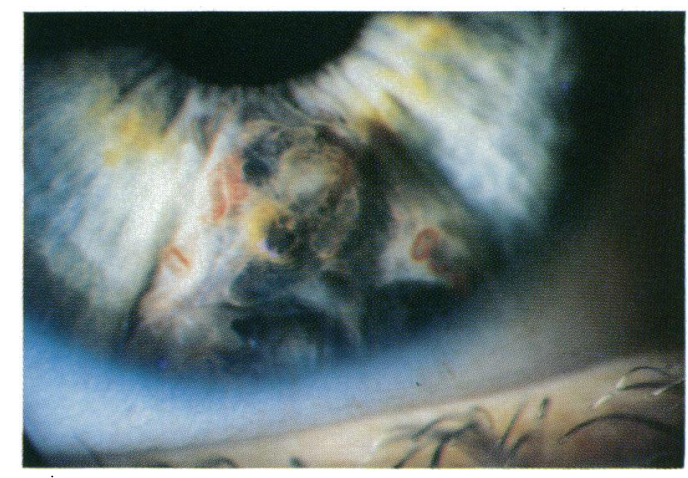

Figure 1 Clinical appearance of the right eye showing a nodular, variably pigmented tumour arising in the inferior iris. 
pigmented and non-pigmented elements (Fig 2). The non-pigmented cells predominated and formed both solid and cystic areas, the latter containing a mucinous material which stained positively for acid mucopolysaccarides with Alcian blue. The non-pigmented cells were eosinophilic, with poorly defined cell borders and counterstained small, mildly hyperchromatic irregular nuclei. Occasional cells contained larger nuclei with a small, but distinct, nucleolus. Mitotic figures were not observed. The pigmented cells, which tended to form strands

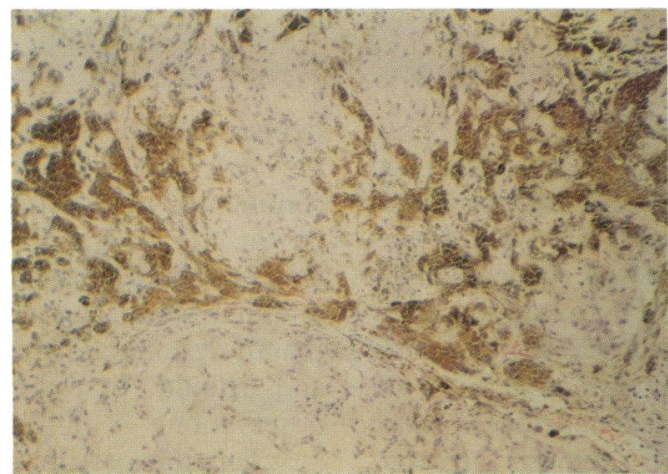

Figure 2 Photomicrograph of the tumour showing the pigmented and non-pigmented cellular elements. Pseudoacin can be seen on the inferior edge of the section (haematoxylin and eosin, magnification $\times 130$ ).

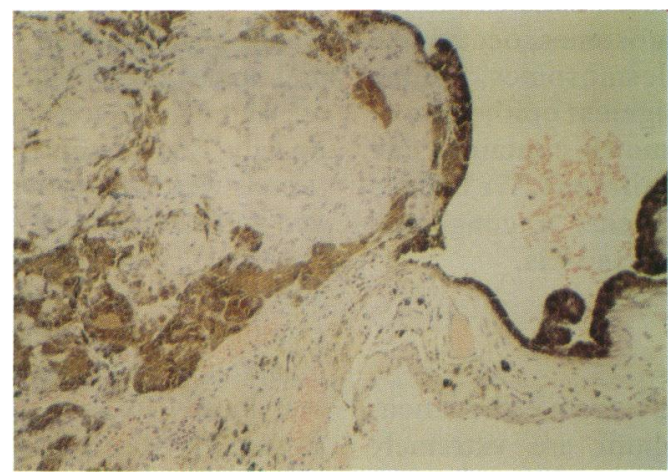

Figure 3 Photomicrograph showing the transition between tumour and normal iris. Normal posterior pigment epithelium can be seen extending over the tumour surface (haematoxylin and eosin, magnification $\times 66$ ).

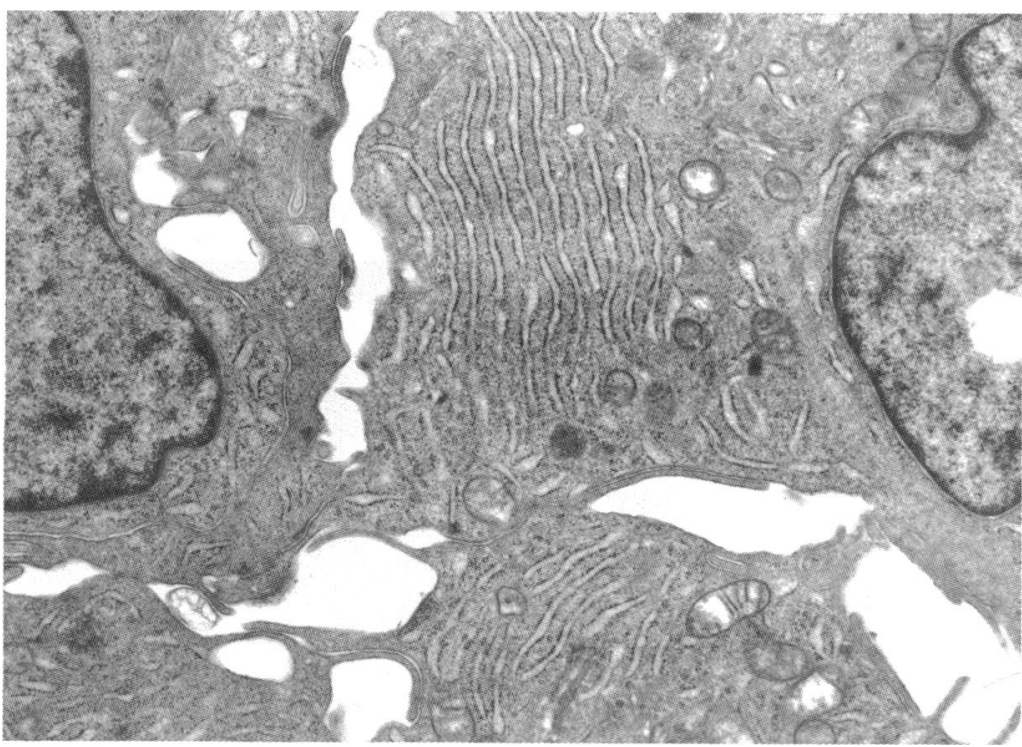

Figure 4 Non-pigmented tumour cells, containing plentiful rough endoplasmic reticulum and numerous mitochondria (magnification $\times 7375$ ). running through the tumour matrix, had a densely pigmented cytoplasm which obscured nuclear detail. Normal iris and ciliary processes were present at opposite ends of the specimen. Ciliary epithelium containing both pigmented and non-pigmented elements extended over the surface of the lesion towards the iris where, after a transitional zone, the epithelium acquired the characteristics of the posterior pigment epithelium of the iris (Fig 3).

\section{ELECTRON MICROSCOPY}

Glutaraldehyde fixed material was submitted for electron microscopy. Both pigmented and nonpigmented cells were readily identified. The non-pigmented cells contained numerous mitochondria and plentiful rough endoplasmic reticulum (Fig 4). In some areas light and dark cells were present. The cell nuclei were elongated with mildly convoluted nuclear membranes, and occasionally contained a small, single nucleolus. The cells had a deeply invaginated plasmalemma, with frequent interdigitations and tight junctions between adjacent cells (Fig 5).

The pigmented cells contained large, round, mature melanosomes, occasional premelanosomes and very occasional mitochondria (Fig 6). Fine fibrils were not observed in these cells which structurally resembled those of the iris posterior pigment epithelium.

Both pigmented and non-pigmented cells were joined by well developed desmosomes and tight junctions (Fig 6). Numerous extracellular spaces (pseudoacini) containing fine collagen fibrils were present throughout the tumour. The cells lining the extracellular spaces had a prominent, often reduplicated, basal lamina (Fig 7).

\section{Discussion}

Acquired neoplasms of the non-pigmented ciliary epithelium usually occur in adults and arise from fully differentiated tissue, in contrast to congenital neoplasms, which are derived from undifferentiated medullary epithelium. ${ }^{14}$ The most common acquired tumour-like lesion is the coronal adenoma (senile hyperplasia, Fuchs' adenoma) which is a pseudoadenomatous hyperplasia of the pars ciliaris. These lesions are rarely diagnosed clinically but are commonly observed in surgical or autopsy specimens. ${ }^{2+25}$ Typically they are small white, often multiple, globular tumours, arising from the pars plicata. They rarely occur before the age of 50 years, but are found with increasing frequency thereafter..$^{2+25}$ Trauma or inflammation may induce a pseudoadenomatous reactive hyperplasia of the ciliary epithelium, which may contain both pigmented and non-pigmented elements. ${ }^{14}$ In contrast, true neoplasms of the ciliary neuroepithelium are extremely rare and most reports are limited to single cases. ${ }^{5-20}$ Adenomas and adenocarcinomas may arise from either the pigmented ${ }^{15-20}$ or nonpigmented ${ }^{5-13}$ ciliary epithelium.

Our case differs from most of those previously reported in several respects: the lesion was first noted in infancy and may well have been congenital; it was observed for more than 17 years $\stackrel{?}{?}$ 


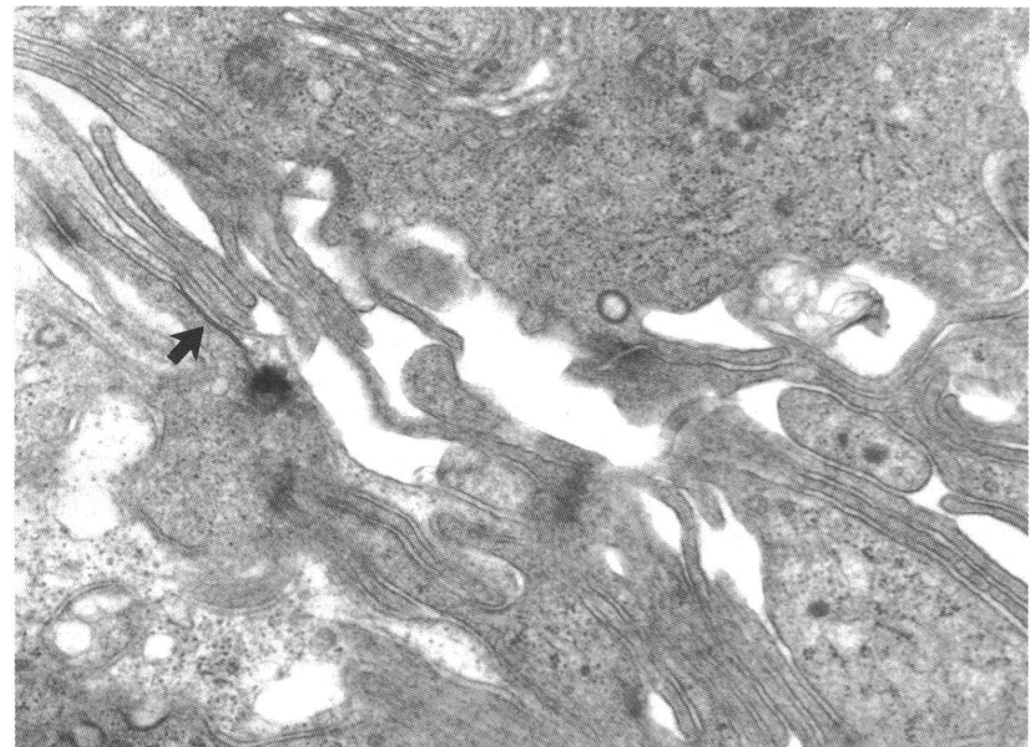

Figure 5 There are complex interdigitating processes and tight junctions (arrow) between adjacent non-pigmented tumour cells (magnification $\times 11800)$.

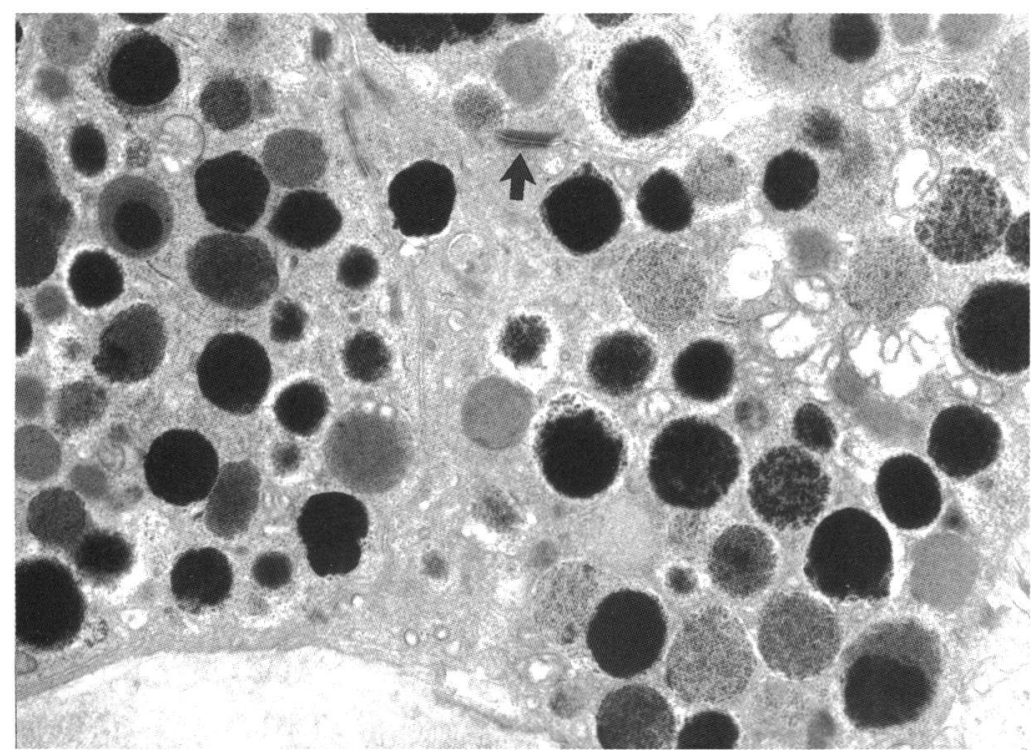

Figure 6 The cytoplasm of pigmented cells with mature, round melanosomes, occasional premelanosomes, and mitochondria. Note the desmosomes (arrow) and tight junctions between the cells (magnification $\times 7375)$.

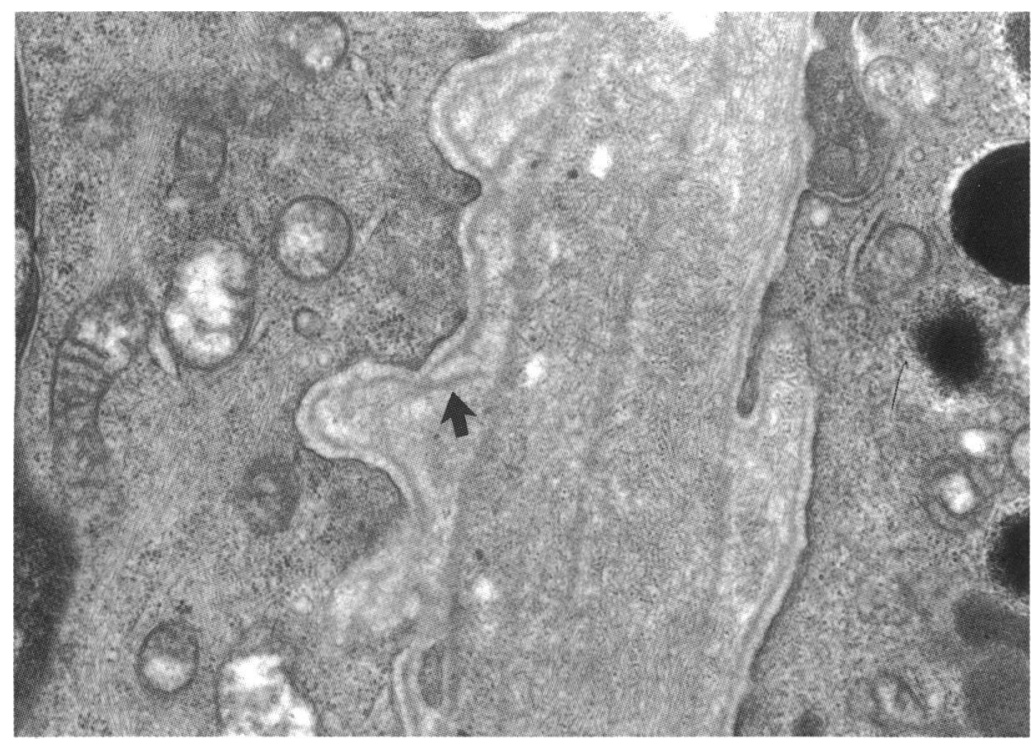

Figure 7 The cells lining an extracellular space have a focally reduplicated basal lamina (arrow) (magnification $\times 11800)$. prior to treatment, and contained both pigmented and non-pigmented cellular elements. If the lesion were present at birth, then it represents an example of a congenital neoplasm which was composed of fully differentiated cellular elements. In this respect the tumour reported herein has similarities with the lesion described as a 'hamartomatous adenoma' of the nonpigmented ciliary epithelium reported by Patrinely $e t a l^{26}$; they reported a case of a slowly enlarging mass arising at the site of a coloboma of the iris and ciliary body of a $2 \frac{1}{2}$ year old infant. Because of its association with a coloboma they felt the tumour represented a hamartoma rather than a conventional adenoma of the ciliary body. It is interesting to note that our neoplasm was also situated inferiorly and was deficient of iris stroma overlying its surface. Ultrastructurally there are similarities between the two lesions; in both cases the lesions contained dark and light non-pigmented cells, which exhibited welldeveloped endoplasmic reticulum, complex plasmalemmal infolding, desmosomes, and tight junctions. In addition, multilaminar basal lamina and spaces containing fine fibrillar material, structurally similar to vitreous, were observed in both lesions. All of these features would suggest that the non-pigmented cells are similar to those of the fully differentiated non-pigmented ciliary epithelium. Our tumour differed from the described by Patrinely $e t a l^{26}$ in that it contained numerous pigmented cells which are structurally similar to those of the normal iris posterior pigment epithelium. The presence of cells which resemble both non-pigmented ciliary epithelium and iris posterior pigment epithelium would suggest that this tumour may have developed during the differentiation of the primitive medullary epithelium in utero, and in this respect it conforms with the classification proposed by Zimmerman.' It differs however, from other congenital lesions (glioneuromas and medulloepitheliomas) in that it is composed entirely of fully differentiated cells; this suggests that the tumour, initiated in utero in the primitive medullary epithelium, may have progressed by division of the two resulting fully differentiated cell types.

The benign nature the lesion is suggested by its relative indolence over a 17 year period. Eventually it was felt that some growth had taken place, although it is possible that this may have been due to an increase in the intercellular matrix (auxetic growth) rather than a proliferation of the cellular elements (multiplicactive growth).

1 Zimmerman LE. The remarkable pleomorphism of tumors of the ciliary epithelium. Trans Aust Coll Ophthalmol 1970; 2:

2 Zimmerman LE. Verhoeff's 'terato-neuroma': a critical reappraisal in light of new observations and current concepts of embryonic tumors. Am f Ophthalmol 1971; 72: 1039-57.

3 Wadsworth JAC. Epithelial tumors of the ciliary body. Am 7 Ophthalmol 1949; 32: 1487-501.

4 Cogan DG, Kuwabara T. Tumors of the ciliary body. Int Ophthalmol Clinic 1971; 11: 27-56.

5 Keyes JE, Moore PG. Adenomatous hyperplasia of the epithelium of the ciliary body. Arch Ophthalmol 1938; 19: 39-46.

6 Burch PG, Maumenee AE. Iridocyclectomy for benign tumors of the ciliary body. Am $\mathcal{F}$ Ophthalmol 1967; 63: 447-52.

7 Fanta $\mathrm{H}$. Epithelial tumor (adenoma) of the ciliary body and iris. Ophthalmologica 1977; 174: 55-7.

8 Haddad R, Slezak H. Benign adenoma of the ciliary epithelium with tumor seeding. Ophthalmologica 1979; 178: 
9 Lommatzsch P, Vorpahl K, Bauke G, et al. Uber epitheliale tumoren des Ziliarkorpers - klinische, histologische und elektronenmikroskopische beobachtungen. Klin Monatsb Augenheilkd 1979; 174: 34-40.

10 Stefani FH, Kment $\mathbf{H}$, Kment $\mathbf{M}$. Adenom des ziliarkorpers. Klin Monatsbl Augenheilkd 1982; 180: 162-3.

11 Dryja TP, Albert DM, Horns D. Adenocarcinoma arising from the epithelium of the ciliary body. Ophthalmology 1981 88: $1290-2$.

12 Shields JA, Augsburger JJ, Waller PH, et al. Adenoma of the nonpigmented epithelium of the ciliary body. Ophthalmolog 1983; 90: 1528-30.

13 Takagi T, Tsuda N, Watanabe F, et al. An epithelioma of the ciliary body. Ophthalmologica 1987; 195: 13-20.

14 Shields JA. Diagnosis and management of intraocular tumors. St Louis: Mosby, 1983: 345-58.

15 Zentmayer WA. A case of hyperplasia of the epithelium of the ciliary processes Arch Ophthalmol 1936; 16: 677-80.

16 Chang M, Shields JA, Wachtel DL. Adenoma of the pigment epithelium of the ciliary body simulating a malignant melanoma. Am f Ophthalmol 1979; 88: 40-4.

17 Wilensky JT, Holland MG. A pigmented tumor of the ciliary body. Arch Ophthalmol 1974; 92: 219-20.
18 Doro S, Werblin TP, Hass B, et al. Fetal adenoma of the pigmented ciliary epithelium associated with persistent hyperplasic primary vitreous. Ophthalmology 1986; 93: 1343-50.

19 Streeten BW, McGraw JL. Tumor of the ciliary pigment epithelium. Am F Ophthalmol 1972; 74: 420-9.

20 Papale JJ, Akiwama K, Hirose T, et al. Adenocarcinoma of the ciliary body pigment epithelium in a child. Arch Ophthalmol $1984 ; 102: 100-3$

21 Morris DA, Henkind P. Neoplasms of the iris pigment epithelium. Am f Ophthalmol 1968; 66: 31-41.

22 Offret H, Saraux H. Adenoma of the iris pigment epithelium. Arch Ophthalmol 1980; 98: 875-83.

23 Shields A. Augsburger JI Sanbrn GE et al Adenoma of the iris-pigment epithelium. Ophthalmology 1983; 90: 735-9.

24 Bateman JB, Foos RY, Coronal adenomas. Arch Ophthalmol 1979; 97: 2379-84.

25 Iliff W, Green WR. The incidence and histology of Fuchs' adenoma. Arch Ophth

26 Patrinely JR, Font RL, Campbell RJ, el al. Hamartomatous adenoma of the non pigmented ciliary epithelium arising in iris-ciliary body coloboma. Ophthalmology 1983; 90: 1540-7. 